\section{International Scientific Journal Theoretical \& Applied Science}

\author{
p-ISSN: 2308-4944 (print) e-ISSN: 2409-0085 (online) \\ Year: $2015 \quad$ Issue: 12 Volume: 32 \\ Published: $30.12 .2015 \quad$ http://T-Science.org
}

\section{Akrom Burkhanovich Akhmedov \\ Head of the Department of Applied Mathematics, \\ Faculty of Aviation,}

Ph.D. in Physics and Mathematics, Associate Professor.

Tashkent State Technical University,

Tashkent, Uzbekistan

akram_akhmedov@inbox.uz

SECTION 2. Applied mathematics. Mathematical modeling.

\title{
NUMERICAL SOLUTION OF DIFFERENTIAL PROBLEMS IN THE SPECTRAL TASKS
}

Abstract: This work is devoted to the numerical resolution of differential approach to the problem of spectral tasks. Justification and effectiveness of the proposed approach is shown by the example of solving the problem of standing waves in plates.

Key words: Numerical solution, spectral problem, standing waves, eigenvalue, a basic function.

Language: English

Citation: Akhmedov AB (2015) NUMERICAL SOLUTION OF DIFFERENTIAL PROBLEMS IN THE SPECTRAL TASKS. ISJ Theoretical \& Applied Science 12 (32): 87-91.

Soi: http://s-o-i.org/1.1/TAS-12-32-16 Doi: crossef http://dx.doi.org/10.15863/TAS.2015.12.32.16

\section{Introduction}

Spectral tasks of significance belong to the category of fundamental problems of mathematical physics. A number of applications are reduced to consideration of the spectral equations having a unique solution only if it is known the value of included parameter. This special parameter is called the characteristic or eigenvalue of the system.

Ordinary approaches for solving dynamic problems is to reduce to an algebraic problem [1] to determine the values of the eigenvalues for the given basis functions. However, it is not always possible to choose the orthonormal coordinate functions for free boundary conditions.

In this regard, permission of differential spectral problems is considered as more effective approach. In this case, the basis functions are defined as the solution of the homogeneous edge value problems. The main aspects of the resolution of differential problems for self-adjoint operators are considered in the work [2].

A numerical approach solutions of differential problem in spectral problems for free boundary conditions, including for nonselfadjoint operators are presented in this paper.

\section{A numerical method for solving spectral problems}

Dynamic problem of the linear theory of elastic $[4,6]]$ for inhomogeneous beams taking into account the structure of the module of rigidity $-\mathrm{D}(\mathrm{x}, \mathrm{t})$ and the shift $-\mathrm{G}(\mathrm{x}, \mathrm{t})$ can be reduced to the following form:

$$
\left[\mathbf{C}(x) \mathbf{V}^{\prime}+\mathbf{Q}(x) \mathbf{V}\right]^{\prime}+\mathbf{A}(x) \mathbf{V}^{\prime}+\mathbf{B}(x) \mathbf{V}-\mathbf{M}(x) \ddot{\mathbf{V}}=\mathbf{F}
$$

in carrying out of initial

$$
\left.\mathbf{V}\right|_{t=0}=\mathbf{V}_{0},\left.\quad \dot{\mathbf{V}}\right|_{t=0}=\mathbf{W}_{0}
$$

and boundary conditions

$$
\mathbf{a}_{\mathbf{x}} \mathbf{V}^{\prime}+\mathbf{b}_{\mathbf{x}} \mathbf{V}=\mathbf{f}_{\mathbf{x}} \quad \text { at } \mathrm{x}=0, l
$$

It should be noted that non-uniform boundary conditions by replacing variables can be reduced to an isotropic form. We apply the method of separation of variables to solve the initial-edge value problem
(1.1) - (1.3), according to which the unknown solution in the form

$$
\mathbf{V}(\mathrm{x}, \mathrm{t})=\mathbf{U}(\mathrm{x}) \mathrm{T}(\mathrm{t})
$$

As a result, we have the following spectral problem 


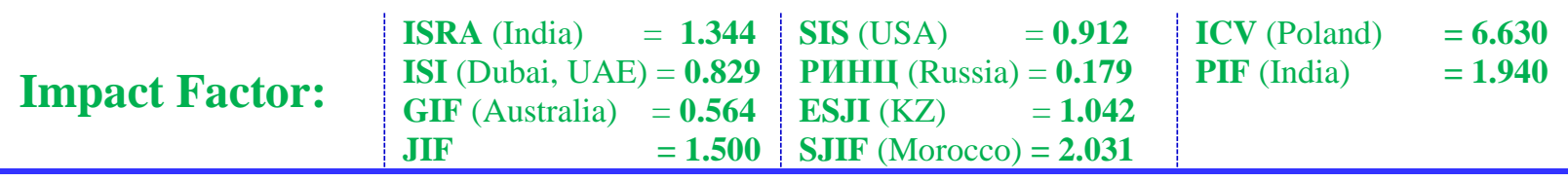

$$
\begin{gathered}
{\left[\mathbf{C}(x) \mathbf{U}^{\prime}+\mathbf{Q}(x) \mathbf{U}\right]^{\prime}+\mathbf{A}(x) \mathbf{U}^{\prime}-[p \mathbf{M}(x)-\mathbf{B}(x)] \mathbf{U}=0} \\
\mathbf{a}_{\mathrm{x}} \mathbf{U}^{\prime}+\mathbf{b}_{\mathrm{x}} \mathbf{U}=0 \quad \text { at } \mathrm{x}=0, l
\end{gathered}
$$

Here the eigenvalue $\mathrm{p}$ is determined from the condition is not trivial solutions of the uniform edge problem (1.5) - (1.6). This edge value problem is solved by differential matrix factorization which uses the following system of uniform differential equations $[7,8]$

$$
\alpha\left[\mathbf{C}(x) \mathbf{U}^{\prime}+\mathbf{Q}(x) \mathbf{U}\right]+\beta \mathbf{U}=0,
$$

by differentiating and comparing with (1.6) to determine $\boldsymbol{\alpha}, \quad \boldsymbol{\beta}, \quad$ taking into account the boundary conditions (1.6) at $\mathrm{x}=0$, we obtain the following Cauchy problem for matrix functions:

$$
\begin{cases}\alpha^{\prime}=[\alpha \mathbf{A}(x)-c] \mathbf{C}^{-1}(x), & \alpha(0)=\mathbf{a}_{0} \mathbf{C}^{-1}(0) \\ \beta^{\prime}=-\alpha[\operatorname{pM}(\mathrm{x})-\mathbf{B}(x)]-\mathbf{Q}(x) & \beta(0)=\mathbf{b}_{0}-\mathbf{a}_{0} \mathbf{C}^{-1}(0) \mathbf{Q}(0),\end{cases}
$$

After determining the required unknowns in the point $x=l$ taking into account (1.6) and (1.7) we have the following system of $2 n$ linear algebraic equations for the unknown $\mathbf{U}(l), \mathbf{U}^{\prime}(l)$

$$
\left(\begin{array}{cc}
\alpha(l) \mathbf{C}(l) & \beta(l)+\alpha(l) \mathbf{Q}(l) \\
a_{l} & b_{l}
\end{array}\right)\left(\begin{array}{l}
\mathbf{U}^{\prime} \\
\mathbf{U}
\end{array}\right)=\left(\begin{array}{l}
0 \\
0
\end{array}\right)
$$

which implicitly depends on the eigenvalue p. It, in its turn is determined from the condition of nontrivial solutions (1.9):

$$
S(p)=\operatorname{det}\left(\begin{array}{c}
d l) \mathbf{C}(l) \\
\mathbf{a}_{l}
\end{array}\right.
$$

Substituting the values of the roots of the equation (1.10) - $\mathrm{p}_{\mathrm{\kappa}}$ in (1.9) we can calculate the values of the basis functions $\mathbf{U}_{\mathrm{K}}^{\prime}(l), \mathbf{U}_{\mathrm{K}}(l)$. Then, using these values, the inverse matrix method of differential speed sweep additionally defined the basis functions on the interval $\mathrm{x} \in[l, 0]$. The

$$
\left(\begin{array}{c}
(l)+\alpha(l) \mathbf{Q}(l) \\
\mathbf{b}_{l}
\end{array}\right)=0
$$

above given scheme is suitable for analytical solutions of the spectral problem. And numerical implementation is based in the Wegstein's iterative process to determine the eigenvalues

$$
\begin{aligned}
& \omega_{1}=p_{1}=S\left(p_{0}\right), p_{n+1}=S\left(\omega_{n}\right), \\
& \omega_{n+1}=p_{n+1}-\frac{\left(p_{n+1}-p_{n}\right)\left(p_{n+1}-\omega_{n}\right)}{\left.p_{n+1}-p_{n}+\omega_{n+1}-\omega_{n}\right)}
\end{aligned}
$$

The condition for the termination of the iterative process is

$$
\mathrm{S}\left(\omega_{\mathrm{n}}\right)<\varepsilon
$$

After the decision of the spectral (1.1) (1.12) the unknown solution of the dynamic problem we expand the eigen functions

$$
\mathbf{V}=\sum_{r=0}^{\infty} T_{r}(t) U_{r}(x)
$$

where $T_{r}(t)$ is a solution of the following differential equations on time

$$
\begin{aligned}
& \ddot{\mathrm{T}}_{\mathrm{r}}(t)+p_{r} T_{r}(t)=f_{r}(t), \\
& T_{r}(0)=T_{r 0}, \quad \dot{T}_{r}(0)=\dot{T}_{r 0},
\end{aligned}
$$




\begin{tabular}{l|lrl|l|ll} 
& ISRA (India) & $=\mathbf{1 . 3 4 4}$ & SIS (USA) & $=\mathbf{0 . 9 1 2}$ & ICV (Poland) & $=\mathbf{6 . 6 3 0}$ \\
Impact Factor: & ISI (Dubai, UAE) $=\mathbf{0 . 8 2 9}$ & PUHU (Russia) $=\mathbf{0 . 1 7 9}$ & PIF (India) & $=\mathbf{1 . 9 4 0}$ \\
& GIF (Australia) & $\mathbf{0 . 5 6 4}$ & ESJI (KZ) & $=\mathbf{1 . 0 4 2}$ & & \\
& JIF & $=\mathbf{1 . 5 0 0}$ & SJIF (Morocco) $=\mathbf{2 . 0 3 1}$ & &
\end{tabular}

$$
\begin{aligned}
& f_{r}(t)=f_{r m} \int_{0}^{l}\left(\mathbf{F}, \mathbf{U}_{r}\right) d x, T_{r 0}=f_{r 0} \int_{0}^{l}\left(\mathbf{V}_{0}, \mathbf{U}_{r}\right) d x, \dot{T}_{r 0}=f_{r 0} \int_{0}^{l}\left(\mathbf{W}_{0}, \mathbf{U}_{r}\right) d x, \\
& f_{r 0}=\int_{0}^{l}\left(\mathbf{U}_{r}, \mathbf{U}_{r}\right) d x, \quad f_{r m}=\int_{0}^{l}\left(m \mathbf{U}_{r}, \mathbf{U}_{r}\right) d x,
\end{aligned}
$$

The solution of the Cauchy can be written as

$$
T_{r}(t)=T_{r 0} \cos \omega t+\dot{T}_{r 0} \omega^{-1} \sin \omega t+\int_{0}^{t} f_{r}(t-\tau) \omega^{-1} \sin \omega \tau d \tau, \quad \omega_{r}^{2}=p_{r}
$$

Thus, we have a complete solution of the linear one-dimensional dynamic problem of elasticity theory of elasticity. However, many applied problems belong to the category of twodimensional dynamic problems whose solution is a rather complicated mathematical problem. Further, the proposed approach to solving onedimensional edge value problems using variational iteration method applies to the solution of twodimensional problems.

\section{Numerical solution of two- dimensional spectral problems}

Two-dimensional dynamic problem of bending of elastic plates and shells in the general case can be written in unified and tensor form [8-10]

$$
\begin{array}{r}
{\left[c_{i j k l} \mathrm{v}_{j, l}+g_{i j k} \mathrm{v}_{j}\right],_{k}+a_{i j k} \mathrm{v}_{i},_{k}+b_{i j} \mathrm{v}_{i}-m_{i j} \ddot{\mathrm{v}}_{i}=q_{i}} \\
d_{i j k} \mathrm{v}_{j, k}+\left.g_{i j} \mathrm{v}_{j}\right|_{\Sigma}=f_{i} \\
\left.\mathrm{v}_{i}\right|_{t=0}=\mathrm{v}_{i}^{0},\left.\quad \dot{\mathrm{V}}_{i}\right|_{t=0}=\mathrm{W}_{i}^{0},
\end{array}
$$

We apply the procedure of separation of variables for the time and coordinates to solve considered problem:

$$
\begin{gathered}
v_{i}(\boldsymbol{x}, t)=V_{i}(\boldsymbol{x}) T(t) \\
{\left[c_{i j k l} V_{j},{ }_{l}+g_{i j k} V_{j}\right]_{k}+a_{i j k} V_{i},_{k}+\left(b_{i j}-p m_{i j}\right) V_{i}=0} \\
\breve{d}_{i j k} V_{j, k}+\left.\breve{g}_{i j} V_{j}\right|_{\Sigma}=0
\end{gathered}
$$

In a Cartesian coordinate system $\mathrm{Ox}_{1} \mathrm{x}_{2}$ can be carry out separation of variables on the coordinate axes

$$
V_{r}\left(x_{1}, x_{2}\right)=X_{1 r}\left(x_{1}\right) X_{2 r}\left(x_{2}\right)
$$

The last expression for the unknown functions $V_{r}$ (2.7) by substituting in (2.5) - (2.6) and performing the procedure of the Bubnov - Galerkin method for each of the coordinate $\mathrm{x}_{\mathrm{s}}(\mathrm{s}=1,2)$, we have a one-dimensional spectral problem for $\mathrm{x}_{\mathrm{s}}$

$$
\begin{gathered}
{\left[\mathbf{C}\left(x_{s}, \mathbf{X}_{p}\right) \mathbf{X}_{s}^{\prime}+\mathbf{Q}\left(x_{s}, \mathbf{X}_{p}\right) \mathbf{X}_{s}\right]^{\prime}+\mathbf{A}\left(x_{s}, \mathbf{X}_{p}\right) \mathbf{X}_{s}-\left[p_{s} M_{s}\left(x_{s}\right)-\mathbf{B}\left(x_{s}, \mathbf{X}_{p}\right)\right] \mathbf{X}_{s}=0} \\
\mathbf{d}_{s x}\left(\mathbf{X}_{p}\right) \mathbf{X}_{s}^{\prime}+\mathbf{b}_{s x}\left(\mathbf{X}_{p}\right) \mathbf{X}_{s}=0 \quad \text { at } \mathbf{X}_{\mathrm{s}}=-1,1
\end{gathered}
$$

Matrix-functions in implicitly form (2.8) contain the unknown functions - $\mathbf{X}_{\mathrm{p}}$, therefore, the resulting eigenvalue problem is to unsplit the unknowns. The main purpose of the reduced spectral problem is a consistent definition of onedimensional basis functions separately for each coordinate. Assuming $\mathbf{X}_{\mathrm{p}}=\mathbf{1}, \mathrm{p}=3-\mathrm{s}$, on $\mathrm{X}_{\mathrm{s}}$, we define the system of basis functions Xs in the 


\begin{tabular}{|c|c|c|c|c|c|c|}
\hline Impact Factor: & $\begin{array}{l}\text { ISRA (India) } \\
\text { ISI (Dubai, UAB } \\
\text { GIF (Australia) } \\
\text { JIF }\end{array}$ & $\begin{array}{r}=1.344 \\
=0.829 \\
=0.564 \\
=1.500\end{array}$ & $\begin{array}{l}\text { SIS (USA) } \\
\text { PИHЦ (Russia) } \\
\text { ESJI (KZ) } \\
\text { SJIF (Morocco) }\end{array}$ & $\begin{array}{l}=0.912 \\
=0.179 \\
=1.042 \\
=2.031\end{array}$ & $\begin{array}{l}\text { ICV (Poland) } \\
\text { PIF (India) }\end{array}$ & $\begin{array}{l}=6.630 \\
=1.940\end{array}$ \\
\hline
\end{tabular}

given one-dimensional problem by the integral expressions corresponding to spectrum of eigenvalues $-\mathrm{p}_{\mathrm{s}}$. In this case, the eigenvalue - $\mathrm{p}_{\mathrm{s}}$ "reduced" one-dimensional spectral problems for each of the coordinate axes are determined from the condition of non-triviality of the homogeneous edge value problems (2.8) - (2.9). For the numerical definition of "reduced" the eigenvalues and the corresponding basis functions will be used computational algorithm (1.7) - (1.12). After determining the basic functions for finding the eigenvalues of the original twodimensional eigenvalue problem using the energy equation of Rayleigh in the form

$$
\left.p_{r t}=\left[\left(c_{i j k l} V_{j, l}+g_{i j k} V_{j}\right)_{, k}+a_{i j k} V_{j, k}+b_{i j k} V_{j}\right) \cdot v_{i}{ }^{(r t)}\right] /\left[m_{i j} V_{j} \bullet v_{i}{ }^{(r t)}\right],
$$

orthonormal basis function, by which the

here $[\mathrm{f} \bullet \mathrm{g}]$ means a component of the decomposition of the scalar product of vector - functions. Here $\mathrm{v}_{\mathrm{i}}{ }^{(\mathrm{rt})}$ - corresponding to the two-dimensional value determined by the $\mathrm{p}_{\mathrm{rt}}$ - eigenvalue.

We expand in basis functions the solution of the spectral problem, the solution of the dynamic problem (2.1) - (2.3)

$$
\mathrm{v}_{\rho}(t, \vec{x})=\sum_{n=0}^{\infty} \sum_{m=0}^{\infty} T_{n m}(t) \mathrm{v}_{\rho}{ }^{(n m)}(\vec{x})
$$

Here the unknown function of time $-T_{n m}(t)$ defined as in (1.14) - (1.16) taking into account the two-dimensionality of the dynamical problem.

The study of the problem of standing waves in isotropic plates under the action of a transverse load is described by the following differential equation in partial derivatives [7], which is written in dimensionless form

$$
\Delta u-\frac{v(1+v)}{2} \frac{q}{E}-\frac{1-v^{2}}{c^{2}} \ddot{u}=0,
$$

where $G=\frac{E h}{1+v}$ is the shear modulus, and $m=\rho h$ - mass per unit length of the plate, $E-$ modulus of elasticity $c^{2}=\frac{E}{\rho}-$ the speed of sound, $v$-Poisson's ratio. This problem lies for free (i.e., the contour of the plate slides without friction) plate, with respect to potential displacement has zero initial and edge conditions.

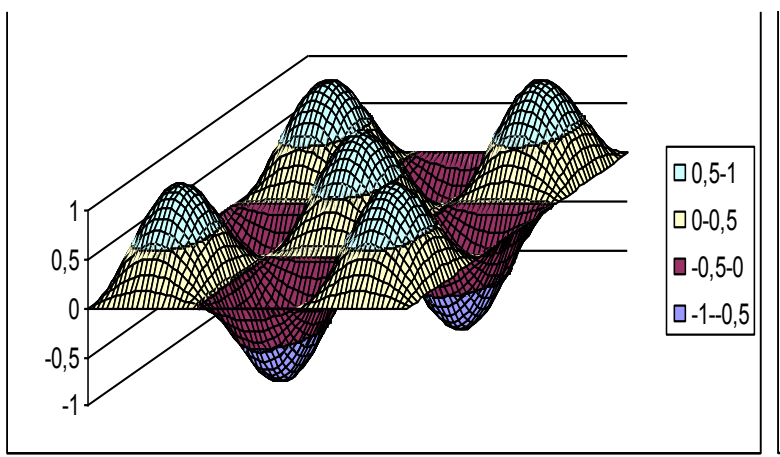

a)

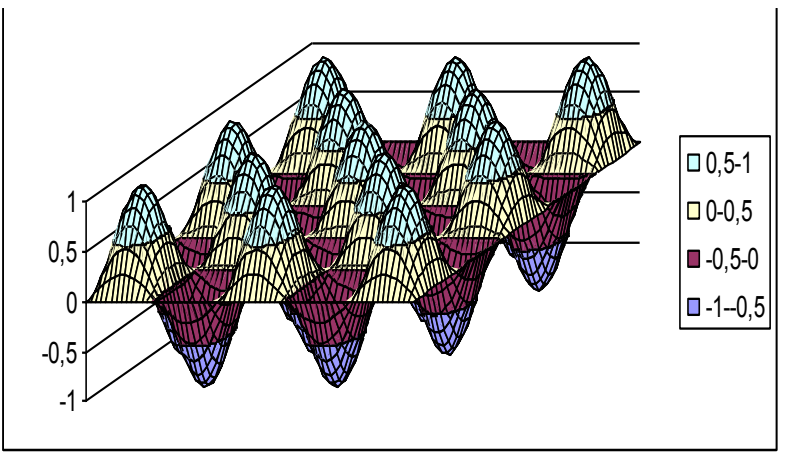

b)

Figure 1

Table 1

\begin{tabular}{|r|r|r|r|r|r|}
\hline$\omega_{k l}$ & 1 & 2 & 3 & 4 & 5 \\
\hline 1 & 4,44 & 7,02 & 9,93 & 12,95 & 16,02 \\
\hline 2 & 7,02 & 8,89 & 11,33 & 14,05 & 16,92 \\
\hline 3 & 9,93 & 11,33 & 13,33 & 15,71 & 18,32 \\
\hline 4 & 12,95 & 14,05 & 15,71 & 17,77 & 20,12 \\
\hline 5 & 16,02 & 16,92 & 18,32 & 20,12 & 22,22 \\
\hline
\end{tabular}

Table 2

\begin{tabular}{|r|r|r|r|r|r|}
\hline$T_{k l}$ & 1 & 2 & 3 & 4 & 5 \\
\hline 1 & 0,01664 & 0 & 0,00061 & 0 & 0,00013 \\
\hline 2 & 0 & 0 & 0 & 0 & 0 \\
\hline 3 & 0,00061 & 0 & $2,2 \mathrm{E}-05$ & 0 & $4,9 \mathrm{E}-06$ \\
\hline 4 & 0 & 0 & 0 & 0 & 0 \\
\hline 5 & 0,00013 & 0 & $4,9 \mathrm{E}-06$ & 0 & $1,0 \mathrm{E}-06$ \\
\hline
\end{tabular}




\begin{tabular}{l|lrl|l|ll} 
& ISRA (India) & $=\mathbf{1 . 3 4 4}$ & SIS (USA) & $=\mathbf{0 . 9 1 2}$ & ICV (Poland) & $=\mathbf{6 . 6 3 0}$ \\
Impact Factor: & ISI (Dubai, UAE) $=\mathbf{0 . 8 2 9}$ & PUHIL (Russia) $=\mathbf{0 . 1 7 9}$ & PIF (India) & $=\mathbf{1 . 9 4 0}$ \\
& GIF (Australia) & $\mathbf{0 . 5 6 4}$ & ESJI (KZ) & $=\mathbf{1 . 0 4 2}$ & & \\
& JIF & $\mathbf{1 . 5 0 0}$ & SJIF (Morocco) $=\mathbf{2 . 0 3 1}$ & &
\end{tabular}

Figure 1 shows the shape of the basis functions, obtained by a numerical approach and the proposed corresponding to different values of the eigenvalues $-\omega_{k l}$ : a) $\omega_{33}=13.33$

$\omega_{55}=22.22$. After solving the reduced onedimensional problem, the known basis functions it can be calculated the values of the eigenvalues for the considered two-dimensional spectral problem on formula (2.10), which is presented in the table 1. Given in Table 1 the numerical values of the eigenvalues correspond to their exact values. It is given the nature of the numerical convergence of the coefficients of an infinite series of the calculated values of basis functions in table 2. As can be seen from the results of an infinite series (2.11) is reached quite fast convergence.

Thus, the proposed numerical approach solution of differential problem in spectral problems for self-adjoint operators of resolving equations proved to be quite effective

\section{References:}

1. Wilkinson J (1970) The algebraic eigenvalue problem. Moscow. "Nauka ", 1970, 537 pages.

2. Kollatts A (1968) Eigenvalue problem. "Nauka", Moscow, 1968, 238 pages.

3. Keldysh MV (1951) On eigenvalues and eigen functions of certain classes of nonselfadjoint equations, DAN, 77, № 1, 1951, 1114 pages.

4. Akhmedov AB (2011) Qualitative analysis of the theory of plates of composite materials .// Uzbek journal Problems of MechanicsTashkent, 2011, -№ 1. -pp.81-84.5.

5. Akhmedov $\mathrm{AB}$ (2012) On the construction of non-linear equations of motion of orthotropic plates. Vestnik MGU, Series 1, Mathematics. Mehanika.2012, № 3.

6. Akhmedov AB (2000) Nonlinear theory of bending vibrations of viscoelastic flat shells //
Uzbek magazine Challenges mehaniki.N January, 2000 pp. 5-8.

7. Akhmedov AB (2012) The numerical solution of spectral problems. Tashko, "Fan". 2012, 118 p.

8. Akhmedov AB, Rashidov TR (2009) Some aspects of the numerical solution of spectral problems // Problems of Uzbek magazine. Tashkent, 2009. - № 5-6. -pp.28-30.

9. Akhmedov AB (2009) The numerical solution of two-dimensional spectral problems // Problems of Uzbek magazine. - Tashkent, 2009. - № 1. - pp.9-13.

10. Akhmedov AB (2006) The numerical analog of the Fourier method for solving spectral problems // DAN Uzbekistan. - Tashkent, 2006. - N4, - pp.47-50. 